\title{
CLINICAL EVALUATION OF TWO TYPES OF CERAMIC INLAYS AND ONLAYS AFTER 6 MONTHS
}

\author{
AVALIAÇÃO CLÍNICA DE INLAYS E ONLAYS CONFECCIONADAS \\ COM DOIS TIPOS DE CERÂMICA, APÓS 06 MESES
}

\author{
Maria Jacinta M. Coelho SANTOS ${ }^{1}$, Carlos Eduardo FRANCISCHONE ${ }^{2}$, Gildo Coelho SANTOS JÚNIOR ${ }^{1}$, Eduardo BRESCIANI ${ }^{3}$ \\ José Carlos ROMANINI ${ }^{4}$, Rosângela SAQUETO ${ }^{5}$, Maria Fidela de Lima NAVARRO ${ }^{6}$
}

\author{
1- DDS, MSc, PhD, Assistant Professor, Department of Operative Dentistry, Dental School, Federal University of Bahia, Brazil. \\ 2- DDS, MSc, PhD, Associate Professor, Department of Operative Dentistry, Bauru Dental School, University of São Paulo, Bauru, SP, Brazil. \\ 3- DDS, MSc, Ph.D Student, Department of Operative Dentistry, Bauru Dental School, University of São Paulo, Bauru, SP, Brazil. \\ 4- Dental technician, Londrina, PR, Brazil. \\ 5- Dental technician, Bauru, SP, Brazil. \\ 6- Associate Professor and Dean of Bauru Dental School, University of São Paulo, Bauru, SP, Brazil.
}

Corresponding address: Maria Fidela de Lima Navarro- Al. Octávio Pinheiro Brisola 9-75 - Vila Universitária - CEP. $17012-901$ -

Bauru-SP Brazil - Phone: 55-14-3234-7688 - Fax: 55-14-3223-4679 - E-mail: mflnavar@usp.br

Received: December 12, 2003 - Returned for modification: March 04, 2004 - Accepted: May 12, 2004

\begin{abstract}

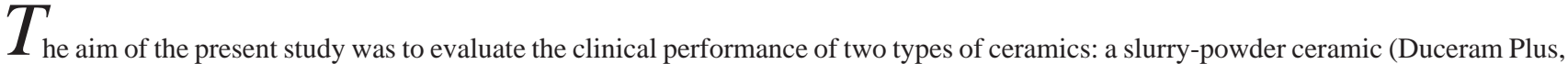
Degussa) - D and a hot-pressed leucite-based glass-ceramic (IPS Empress, Ivoclar Vivadent) - IPS. Eighty-six restorations, 44 IPS and 42 $\mathrm{D}$, were made by one operator. A total of 33 onlays and 53 inlays on twenty-seven premolars and 59 molars were cemented in 35 patients of both sexes, mean age 35 years. All restorations were cemented with the dual-resin cement (Variolink, Ivoclar-Vivadent) under rubber dam and were evaluated at the baseline and after six months, using the modified U.S.P.H.S. criteria for postoperative sensitivity, secondary caries, fracture, color match, marginal discoloration, marginal integrity and surface texture. Additionally radiographs and intraoral photographs were carried out. At baseline 86 restorations were analyzed and all of them received Alfa rating, except for the following that received Bravo rating for postoperative sensitivity - IPS (2.27\%); D (7.14\%); for color match - IPS (2.27\%); D (2.38\%) and for surface texture - IPS (2.27\%); D (11.90\%). After 6 months $100 \%$ of the restorations were analyzed and the following received Bravo rating: color match - IPS (4.55\%) and D (9.52\%); surface texture - IPS (2.27\%) and D (11.9\%); marginal discoloration - IPS (6.82\%) and D (4.76\%) and marginal integrity - IPS (4.55\%) and D (7.14\%). The results were submitted to the Fisher and McNemar Statistical Tests. No significant differences were noticed between the two ceramics. Both ceramics demonstrated satisfactory clinical performance after six months.

Uniterms: Ceramic; Inlay; Onlay; Esthetic restoration; Clinical study.
\end{abstract}

\section{RESUMO}

$E$ trabalho se propôs a avaliar a performance clínica de dois tipos de cerâmica: IPS Empress, Ivoclar-Vivadent - IPS e Duceram Plus, Degussa - D. Foram realizadas 86 restaurações por apenas um operador, sendo 44 IPS e 42 D. Vinte e sete pré-molares e 59 molares, num total de 33 onlays e 53 inlays, foram cimentadas em 35 pacientes de ambos os sexos, com idade média de 35 anos. A cimentação das restaurações foi realizada com cimento resinoso dual (Variolink, Ivoclar-Vivadent) sob isolamento absoluto e avaliadas no baseline e após 06 meses, mediante o critério U.S.P.H.S. modificado, quanto à sensibilidade pulpar, reincidência de cárie, fratura, reprodução de cor, descoloração marginal, integridade marginal e textura superficial. Adicionalmente foram realizadas radiografias e fotografias. No baseline foi obtida a classificação Bravo nos itens sensibilidade pulpar - IPS (2,27\%); D (7,14\%); reprodução de cor - IPS (2,27\%); D (2,38\%) e textura superficial - IPS (2,27\%); D (11,90\%). Após 06 meses foram analisadas as 86 restaurações, nas quais foi constatada a classificação Bravo para os itens reprodução de cor - IPS (6,82\%); D (2,38\%); textura superficial - IPS (2,27\%); D (9,52\%); descoloração marginal - IPS (6,82\%); D (4,76\%) e integridade de superfície- IPS (4,55\%); D (7,14\%). Os resultados obtidos foram submetidos ao Teste Estatístico de Fisher e McNemar. Não houve diferença estatisticamente significante entre as cerâmicas. Pode-se concluir que os dois tipos de cerâmica demonstraram uma performance clínica satisfatória após 06 meses.

Unitermos: Cerâmica; Inlay; Onlay; Restauração estética; Estudo clínico. 


\section{INTRODUCTION}

In recent years, patients have developed increasing interest in tooth-colored nonmetallic restorations, influenced by media publicity, as well as uncertainty regarding the toxicity of mercury-containing amalgams ${ }^{3}$. Several esthetic materials are available in the market, including glass ionomer cements, hybrid ionomers, resin composites and ceramics. In the last few years, many types of all-ceramic materials, with high values of compressive strength, have been developed and improved adhesive techniques have enabled their use in many clinical situations ${ }^{19}$. Among these materials, a hot-pressed leucite-reinforced glass-ceramic, the IPS Empress system (Ivoclar-Vivadent, Schaan, Leichtenstein), has been designed for the fabrication of tooth-colored inlays, onlays and full crowns ${ }^{16,28}$. The IPS Empress is basically a feldspathic ceramic delivered in cylindrical ingots, in which the leucite crystals are already present in the ceramic ingots, due to preceraming during fabrication ${ }^{9,22}$. Luthy, et al. ${ }^{16}$ (1992) stated that the heat-pressing technique significantly improved the flexure strength (three-point bending test) of this material, and reported a mean value of $182 \mathrm{MPa}$. Neiva, et al. ${ }^{21}(1998)$ and Chai, et al. ${ }^{4}$ (2000) compared the in vitro fracture resistance of some all-ceramic systems cemented with an adhesive technique and reported no statistically significant differences between IPS Empress, In-Ceram and Procera systems.

Nowadays, many techniques and systems are available for fabricating all-ceramic restorations. They may be sintered, milled, infiltrated, pressed or cast ${ }^{2}$.

Some studies ${ }^{8,12,14,16}$ have referred to long-term clinical performance of all-ceramic systems for short and long periods. In 1998, Hayashi, et al. ${ }^{12}$ evaluated in a prospective study the clinical behavior of 49 fired ceramic inlays (G-Cera Cosmotech II) over a period of 6 years. They reported marginal fracture in 6 restorations (13\%) and marginal discoloration in 11 (23\%). SEM evaluation showed wear of resin cement along margins in 36\% at 6 years. They observed that marginal fractures were related to wear of resin cement and consider that resin cements with improved physical properties are urgently needed. In a 1998 prospective study, Fuzzi and Rappelli ${ }^{8}$ examined 183 fired ceramics (Microbond Natural-Austenal Dental; Fortune-Willians, Ivoclar) after an observation period of 10 years. Only 5 restorations failed. Four failures were in molar teeth while the other was in a premolar tooth. Of these failures, four were related to endodontic problems and one was due to fracture. They reported a success rate of $97 \%$ at 10 years. In 1999 Krämer, et al. ${ }^{14}$ investigated in a prospective study the clinical performance of 96 IPS Empress inlays. The failure rate after four years was 7\%. Four inlays were failed for bulk fracture and three teeth required endodontic treatment. The $79 \%$ of surviving restorations exhibited significant deterioration in marginal adaptation. In 2000 Felden, et al. ${ }^{6}$ reported the results of a 7-year investigation of 42 IPS Empress restorations, using the USPHS criteria. One restoration had failed during the study (2.4\%). The clinical evaluation of the marginal adaptation revealed Alfa ratings for 28 restorations
(66.7\%), Bravo ratings for 12 restorations (28.6\%) and Delta ratings for 2 restorations (4.7\%). No Charlie ratings were found. The probability of survival over a period of 7 years was $81 \%$.

Many reasons have been given for the failure of allceramic restorations. The principal problems associated with the ceramic inlay appear to be related to cavity preparation, patient occlusion, cementing agents, insufficient thickness and internal defects of ceramics, 5,6,13,14,15,26. Because of the importance of ceramic materials in esthetic dentistry, this study aimed at evaluating the clinical behavior of two types of ceramics: Duceram - Plus (Degussa, Ducera, Rosbach, Germany) and IPS Empress (Ivoclar-Vivadent, Schaan, Leichtenstein), according to modified USPHS criteria, as a restorative alternative for posterior teeth. The null hypotheses were that no difference would be found between the two systems, as well as between inlay and onlay restorations and between restorations placed in premolar or molar teeth.

\section{METHOD AND MATERIALS}

Thirty-five patients, including 17 females and 18 males, with a mean age of 35 years, who required inlay and onlay restorations, were selected for this study. The volunteers underwent careful anamnesis and the following items were considered as exclusion criteria: high caries risk; periodontal disease; presence of removable or fixed orthodontic appliance; signs of bruxism or clenching; absence of more than one tooth in the posterior region; poor oral hygiene; and pregnancy.

All patients were treated at Bauru Dental School, University of São Paulo, SP, Brazil. The patients were informed about the research methodology, risks and benefits, as well as informed about their rights to quit participating in this research at any time. A written informed consent was requested. The study was carried out according to research norms and guidelines for human beings, deriving from Resolution \# 196, approved on October, 1996 by the National Health Council and Ethics Research Committee from the Bauru Dental School, University of São Paulo, SP, Brazil.

Eighty-six inlays and onlays in class II cavities were made in 27 premolars and 59 molars, by one operator, to create a standardized cavity preparation. A total of 33 onlays and 53 inlays were made with two types of ceramics: 42 slurry-powder ceramic restorations (Duceram - Plus - D) and 44 hot-pressed ceramic restorations (IPS Empress - IPS).

The isthmus width was established between 1.5 to $2.0 \mathrm{~mm}$; the pulpal floor depth was between 1.5 to $2.0 \mathrm{~mm}$; the axial wall depth was $1.5 \mathrm{~mm}$; the internal line angles were rounded and the divergence angle of the cavity was approximately $10^{\circ}$ to $15^{\circ}$, with no bevel. The undercuts were covered with resin-modified glass ionomer (Vitremer, 3M Dental Products Div., St. Paul, MN, USA) to achieve the cavity form by removing the build-up material, in order to preserve sound tooth structure. The tooth was prepared by means of a tapered rounded diamond tip in high speed \# 4137, \# 2133, 
\#4138 (KG Sorensen Ind. Com. Ltda, São Paulo, SP, Brazil), with water spray. The enamel margins were subsequently finished using hand instruments.

After finishing the cavity preparation, the provisional restorations were fabricated with the use of self-curing acrylic resin (Duralay - Reliance Dental Mfg Co. Worth, IL, USA) and fixed with eugenol-free cement (Temp Bond NE, Kerr, Karlsruhe, Germany).

Full-arch impressions were taken with a polyvinylsiloxane material (Express, 3M Dental) from the prepared arches and with irreversible hydrocolloid (Jeltrate-Dentsply International Inc., Pennsylvania, USA) from the antagonist arches. Both models were poured with dental stone (Durone, Dentsply). The bite-records were made by a polyvinylsiloxane material (Bite Registration, 3M Dental). Two dental ceramists were selected to produce the inlays and onlays, whose colors were selected from the Vita shade guide (Vita Zahnfabrick, Bad Sackingen, Germany).

The intraoral fit was evaluated under rubber dam and the internal adjustments performed using diamond burs (KG Sorensen) with low speed. When the fitting was not considered satisfactory, the restoration was rejected. Only two restorations were repeated.

Following adjustments, the internal surfaces were sandblasted with $50-\mathrm{mm}$ aluminum oxide particles at a pressure of 6 bars (Opiblast, Buffalo Dental Mfg., Inc. NY, USA). Then, these surfaces were etched with $10 \%$ hydrofluoric acid (Dentsply) for 60 seconds, washed and the silane agent (Monobond S, Ivoclar-Vivadent) applied for 60 seconds and dried. The cavity was cleaned with pumice slurry and etched with 35\% phosphoric acid gel for 15 seconds, rinsed with water and gently air-dried, taking care to avoid desiccation of the tooth substrate. The dentinal surface was treated with a dentin bonding agent Syntac Primer (applied for 15 seconds and dried) and Syntac Adhesive (applied for 10 seconds and dried), both products from Ivoclar-Vivadent. Subsequently, the cavity preparation and inner surface of the ceramic inlays were covered with a layer of bonding agent (Heliobond, Ivoclar-Vivadent), which was air-thinned but not light-cured. The dual resin cement Variolink II (Ivoclar-Vivadent) was used for cementation (base + catalyst 1:1) of all inlays and onlays, according to the manufacturer's instructions. Polymerization of the luting agent was performed by light-curing for a total of 120 seconds from different positions (40 seconds in each direction).

After light-curing, the rubber dam was removed and the occlusal contacts were adjusted with diamond finishing burs \# 3202F and \#3203 FF (KG Sorensen), under water cooling. The surfaces were carefully polished with rubber tips (Cerapol Plus - Edenta AG Dental Rotary Instruments, Hauptstrasse, Switzerland) and the final polishing was conducted using felt discs with diamond polishing gel (KG Sorensen).

One week following placement, the restorations were assessed according to the modified United States Public Health Service (USPHS) criteria ${ }^{23}$ (Figure 1), by two independent investigators, using mirrors and probes. In addition, bitewing radiographs and intraoral photographs were made. The same procedures performed at the baseline were done after 6 months.

\section{RESULTS}

All restorations were examined at the baseline and after 6 months. The ratings Alpha and Bravo were considered as successful. An overview of the results is shown in Figure 2. At the baseline, all restorations received Alfa rating, except for the following that received Bravo ratings for: postoperative sensitivity - IPS (2.27\%); D (7.14\%); color match - IPS (2.27\%); D (9.52\%) and surface texture - IPS (2.27\%); D (11.9\%). After 6 months, all 86 restorations were analyzed and all of them received Alfa rating, except for the following that received Bravo ratings for: color match - IPS (4.55\%); D (9.52\%); surface texture-IPS (2.27\%); D (11.9\%); marginal discoloration - IPS (6.82\%); D (4.76\%) and marginal integrity - IPS (4.55\%); D (7.14\%).

The patients who presented Bravo rating for postoperative sensitivity at the baseline were questioned after six months and reported absence of pain, transforming the Bravo rating into Alpha. No Charlie or Delta ratings were observed at six months. The patients were satisfied with the treatment carried out. The results were submitted to the Fisher and McNemar Statistical Tests. The Fisher statistical test revealed no significant difference between Duceram and IPS Empress ceramic systems for all aspects evaluated ( $p>0.05)$. With regard to the clinical behavior of ceramic inlay and onlay restorations, as well as the restorations placed in premolar or molar regions, the Fisher Test showed no statistical difference. The McNemar statistical test was used to draw a comparison between baseline and six months for each ceramic system. No significant difference was detected between the baseline and six months, for the ceramic restorations of each system $(\mathrm{p}>0.05)$.

\section{DISCUSSION}

The present study investigated a total of 86 inlay and onlay ceramics placed in 35 patients using two systems: Duceram and IPS Empress. The results showed the clinical performance of these restorations at six months. This period is short, but this study aims at a continuous and long-term evaluation.

All restorations were examined according to the modified USPHS criteria ${ }^{23}$ by two investigators calibrated in the use of the system. The investigators worked as a team, although independently. Whenever there was a disagreement on the rating of a given restoration, joint examination was performed to solve the disagreement. Determination of interexaminer reliability yielded Kappa values above 0.85 for all criteria, giving evidence of high agreement between examiners. The majority of restorations received Alfa rating for all the characteristics studied; some patients presented 
postoperative sensitivity at the baseline (IPS - $2.27 \%$ and D $-7.14 \%$ ), but it rapidly reduced in about two weeks. The presence of postoperative sensitivity has been reported, especially in the adhesive inlay technique, due to incomplete sealing of the dentin ${ }^{14,26}$. In the present study, the deep dentine was protected with calcium hydroxide cement (Dycal, Dentsply) and resin-modified glass ionomer (Vitremer, 3M Dental).

\begin{tabular}{|c|c|c|}
\hline Characteristic & Rating & Criteria \\
\hline $\begin{array}{l}\text { Secondary } \\
\text { caries }\end{array}$ & $\begin{array}{l}\text { Alpha } \\
\text { Bravo }\end{array}$ & $\begin{array}{l}\text { No evidence of caries contiguous with the margin of the restoration. } \\
\text { Caries evident contiguous with the margin of the restoration. }\end{array}$ \\
\hline $\begin{array}{l}\text { Marginal } \\
\text { discoloration }\end{array}$ & $\begin{array}{l}\text { Alpha } \\
\text { Bravo } \\
\text { Charlie }\end{array}$ & $\begin{array}{l}\text { No discoloration on the margin between the restoration and the tooth structure. } \\
\text { Discoloration on the margin between the restoration and the tooth structure. } \\
\text { Discoloration has penetrated along the margin of the restorative material in a pulpal } \\
\text { direction. }\end{array}$ \\
\hline $\begin{array}{l}\text { Surface } \\
\text { texture }\end{array}$ & $\begin{array}{l}\text { Alpha } \\
\text { Bravo } \\
\text { Charlie }\end{array}$ & $\begin{array}{l}\text { Smooth surface. } \\
\text { Slightly rough or pitted, can be refinished. } \\
\text { Rough, cannot be refinished. }\end{array}$ \\
\hline $\begin{array}{l}\text { Marginal } \\
\text { integrity }\end{array}$ & $\begin{array}{l}\text { Alpha } \\
\text { Bravo } \\
\text { Charlie } \\
\text { Delta }\end{array}$ & $\begin{array}{l}\text { No visible evidence of ditching along the margin. } \\
\text { Visible evidence of ditching along the margin not extending to the DE junction. } \\
\text { Dentin or base is exposed along the margin. } \\
\text { Restoration is mobile, fractured or missing. }\end{array}$ \\
\hline Color match & $\begin{array}{l}\text { Alpha } \\
\text { Bravo } \\
\text { Charlie }\end{array}$ & $\begin{array}{l}\text { No mismatch in color, shade and translucency between restoration and adjacent } \\
\text { tooth structure. } \\
\text { Mismatch between restoration and tooth structure within the normal range of color, } \\
\text { shade and translucency. } \\
\text { Mismatch between restoration and tooth structure outside the normal range of } \\
\text { color, shade and translucency. }\end{array}$ \\
\hline Fracture & $\begin{array}{l}\text { Alpha } \\
\text { Bravo }\end{array}$ & $\begin{array}{l}\text { No evidence of fracture. } \\
\text { Evidence of fracture. }\end{array}$ \\
\hline
\end{tabular}

FIGURE 1- Modified USPHS criteria for the clinical evaluation of ceramic inlays and onlays used in this study

\begin{tabular}{|c|c|c|c|c|}
\hline \multirow{2}{*}{$\begin{array}{l}\text { Investigation } \\
\text { "Alpha" }\end{array}$} & \multicolumn{2}{|c|}{ Baseline } & \multicolumn{2}{|c|}{6 Months } \\
\hline & IPS (\%) & Duceram (\%) & IPS (\%) & Duceram (\%) \\
\hline Postoperative sensitivity & 97.73 & 92.86 & 100.00 & 100.00 \\
\hline Secondary caries & 100.00 & 100.00 & 100.00 & 100.00 \\
\hline Fracture & 100.00 & 100.00 & 100.00 & 100.00 \\
\hline Color match & 97.73 & 90.48 & 95.45 & 90.48 \\
\hline Marginal discoloration & 100.00 & 100.00 & 93.18 & 95.24 \\
\hline Marginal integrity & 100.00 & 100.00 & 95.45 & 92.86 \\
\hline Surface texture & 97.73 & 88.10 & 97.73 & 88.10 \\
\hline
\end{tabular}

FIGURE 2- "Alpha" results of the clinical investigation with the modified USPHS criteria 
Alhadainy, et al. ${ }^{1}$ (1998) pointed out that in clinical research there are some uncontrolled variables, due to individual variations such as tooth size, cavity size and occlusal force, with standardization of the cavity form being important in order to minimize the effect of these variables. In the present study, the resin-modified glass ionomer was used as a base to block out the undercuts, helping to standardize the depth of pulpal floor (from 1.5 to $2.0 \mathrm{~mm}$ ) and reducing the loss of tooth substance during cavity preparation, to achieve divergent walls. According to Moscovich, et al. ${ }^{20}$ (1998), a significant amount of sound tooth structure was removed to transform a direct restorative preparation into an adhesive inlay preparation.

The color match presented some Bravo ratings at the baseline, IPS (2.27\%) and D (9.52\%), probably due to stained teeth caused by the old restoration, having a slight mismatch in color between the restoration and tooth structure. At the 6-month evaluation, the Duceram ceramic restorations presented the same Bravo ratings for color match; nevertheless, for the IPS Empress ceramic restorations, the Bravo ratings increased to $4.55 \%$. This can be explained by the fact that the IPS Empress ceramic suffers an extrinsic painting before glazing, which can be removed during the occlusal adjustments. On the other hand, the Duceram ceramic is made by layers, undergoing intrinsic painting. In a retrospective study of IPS Empress crowns, 13\% exhibited a mismatch in color ${ }^{24}$.

Marginal discoloration and marginal integrity showed Bravo ratings for IPS (6.82\%); D (4.76\%) and IPS (4.55\%); D (7.14\%), respectively. Fradeani, et al. ${ }^{7}$ (1997) reported that marginal discoloration and marginal integrity were interrelated and both would deteriorate with time. This fact can be attributed to the wear of luting resin cement, which is considered as one critical aspect of adhesively luted ceramic restorations ${ }^{11,12}$. This fact can be confirmed by some prospective studies, in which the marginal adaptation is the criterion with the lowest Alfa ratings ${ }^{7,10-12,14,17,18}$. The intraoral fit was evaluated under rubber dam and considered excellent, with only two inlays being returned to the laboratory to be repeated. Hayashi, et al. ${ }^{10}$ (2000) observed that MOD inlay ceramics is more difficult to adapt due to its more complex form. However, in this study, the inlays and onlays showed a good fit, with minimum internal adjustments, confirming the importance of using a qualified laboratory technician, as well as the fact that minimum adjustments are necessary to prevent micro-cracks ${ }^{17}$.

The Duceram ceramic restorations presented more Bravo ratings in surface texture when compared with the IPS Empress ceramic restorations, D (11.9\%) and IPS (2.27\%); however, these values did not demonstrate significant differences between them. Sjögren, et al. ${ }^{24}$ (1992) and Hayashi, et al. ${ }^{12}$ (1998) emphasized that the presence of rough surfaces could be associated with inadequate polishing. Studer, et al. ${ }^{26}$ (1996) and Tidehag and Gunne ${ }^{27}$ (1995) reported high Alfa ratings for surface texture with IPS Empress. The other criteria analyzed, such as postoperative sensitivity, secondary caries and fracture obtained $100 \%$ of Alpha ratings for both ceramics.
Various authors have reported that an adequate preparation is necessary for the prevention of fractures ${ }^{5,6,25}$. In the present study, all cavities were prepared by one operator, aiming at standardization. Another important factor to prevent fracture is related to luting cements. In this study, all inlays and onlays were cemented using an adhesive luting technique and were placed with a dual resin cement (Variolink II, Ivoclar-Vivadent). No fracture was observed in the present study.

The patients reported satisfaction with the restoration results. Both types of ceramics showed an excellent clinical performance at six months, in both premolar and molar teeth, according to findings in other studies ${ }^{8,11,27}$. However, longterm studies are required to better evaluate the clinical performance of ceramic inlays and onlays.

\section{CONCLUSIONS}

- The evaluated restorative systems achieved satisfactory results at six months.

- No secondary caries or fracture was observed in this period.

- The null hypotheses that no difference would be found between the two systems, as well as between inlay and onlay restorations and between restorations placed in premolar or molar teeth were accepted.

\section{ACKNOWLEDGMENT}

- The authors would like to thank IVOCLAR-VIVADENT and DEGUSSA for supporting this study.

\section{REFERENCES}

1- Alhadainy HA, Abdel-Aziz AH, Abdel-Kerein UM. Clinical evaluation of repairing old amalgam restorations with composite inlays. Am J Dent 1998; 11:134-6.

2- Anusavice KJ. Reducing the failure potential of ceramic-based restorations. Gen Dent 1997; 45:30-5.

3- Arenholt-Bindslev D. Dental amalgam - environmental aspects. Adv Dent Res 1992;6: 125-30.

4- Chai J, Takahashi Y, Sulaiman F, Chong K, Lautenschlager, EP. Probability of fracture of all-ceramic crowns. Int J Prosthodont 2000; 13: $420-4$

5- Donovan TE, Chee WWL. Conservative indirect restorations for posterior teeth. Cast versus bonded ceramic. Dent Clin North Am 1993; 37: 433-43.

6- Felden A, Schmalz G, Hiller KA. Retrospective clinical study and survival analysis on partial ceramic crowns: results up to 7 years. Clin Oral Investig 2000; 4: 199-205.

7- Fradeani M, Aquiliano A, Bassein L. Longitudinal study of pressed glass-ceramic inlays for four and half years. J Prosthet Dent 1997; 78: 346-56. 
8- Fuzzi M, Rappelli G. Survival rate of ceramic inlays. J Dent 1998; 26: $623-6$

9- Gorman CM, McDevitt WE, Hill RG. Comparison of two heatpressed all-ceramic dental materials. Dent Mater 2000; 16: 389-95.

10- Hayashi M, Miura M, Nishimura N, Takeshige F, Ebisu S. Effects of cavity form and setting expansion of refractory dies on adaptability of Class II (MO and MOD) fired ceramic inlays. Oper Dent 2000; 25: 549-54.

11- Hayashi M, Tsuchitani Y, Kawamura Y, Miura M, Takeshige F, Ebisu S. Eight-year clinical evaluation of fired ceramic inlays. Oper Dent 2000; 25: 473-81.

12- Hayashi M, Tsuchitani Y, Miura M, Takeshige F, Ebisu S. 6-year clinical evaluation of fired ceramic inlays. Oper Dent 1998; 23: 318326.

13- Isidor F, Brondum K. A clinical evaluation of porcelain inlays. J Prosthet Dent 1995;74:140-3.

14- Krämer N, Frankenberger R, Pelka M, Petschelt A. IPS Empress inlays and onlays after four years - a clinical study. J Dent 1999; 27: 325-31.

15- Leevailoj C, Platt JÁ, Cochran MA, Moore K. In vitro study of fracture incidence and compressive fracture load of all-ceramic crowns cemented with resin-modified glass ionomer and other luting agents. J Prosthet Dent 1998; 80: 699-707.

16- Luthy H, Wohlwend A, Schärer P. Heat-pressed ceramics: technology and strength. Int J Prosth 1992; 5: 9-16.

17- Mabrito C, Roberts M. Porcelain onlays. Curr Opin Cosmet Dent 1995; 7: 1-8.

18- Manhart J, Scheibenbogen A, Chen HY, Hickel R. A 2-year clinical study of composite and ceramic inlays. Clin Oral Invest 2000; 4: 192-8.
19- Mesaros AJ, Evans DB, Schwartz RS. Influence of a dentin bonding agent on the fracture load of Dicor. Am J Dent 1994; 7: 137-40.

20- Moscovich H, Creugers NHJ, Kanter RJAM, Roeters FJM. Loss of sound tooth structure when replacing amalgam restorations by adhesive inlays. Oper Dent 1998;15: 327-31.

21- Neiva G, Yaman P, Dennison JB, Razoog ME, Lang BR. Resistance to fracture of three all-ceramic systems. J Esthet Dent 1998; 10: 60-

22- Pröbster L, Geis-Gerstorfer, J, Kirchner, E, Kanjantra, P. In vitro evaluation of a glass- ceramic restorative material. J Oral Rehab 1997; 24: 636-45.

23- Ryge G. Clinical criteria. Int Dent J 1990; 30: 347-58.

24- Sjögren G, Lantto R, Granberg A, Sundström BO, Tillberg A. A clinical examination of leucite reinforced glass-ceramic crowns (Empress) in general practice: a retrospective study. Int J Prosthodont 1999; 12: 122-8.

25- Stenberg R, Matsson L. Clinical evaluation of glass ceramic inlays (Dicor). Acta Odont Scand 1993; 51: 91-7.

26- Studer S, Lehrer C, Brodbeck U, Schärer P. Short-term results of IPS-Empress inlays and onlays. J Prosthodont 1996; 5: 277-87.

27- Tidehag P, Gunne J. A 2-year clinical follow-up study of IPS Empress ceramic inlays. Int J Prosthodont 1995; 8: 456-60.

28- Uctasli S, Wilson HJ, Unterbrink G, Zaimoglu A. The strength of a heat-pressed all-ceramic restorative material. J Oral Rehab 1996; 23: 257-61. 